\title{
Microevolution of Puumala hantavirus during a Complete Population Cycle of Its Host, the Bank Vole (Myodes glareolus)
}

\author{
Maria Razzauti ${ }^{1,2 *}$, Angelina Plyusnina ${ }^{1}$, Heikki Henttonen², Alexander Plyusnin ${ }^{1}$ \\ 1 Department of Virology, Haartman Institute, University of Helsinki, Helsinki, Finland, 2 Finnish Forest Research Institute, Vantaa, Finland
}

\begin{abstract}
Microevolution of Puumala hantavirus (PUUV) was studied throughout a population cycle of its host, the bank vole (Myodes glareolus). We monitored PUUV variants circulating in the host population in Central Finland over a five-year period that included two peak-phases and two population declines. Of 1369 bank voles examined, 360 (26.3\%) were found infected with PUUV. Partial sequences of each of the three genome segments were recovered (approx. 12\% of PUUV genome) from 356 bank voles. Analyses of these sequences disclosed the following features of PUUV evolution: 1) nucleotide substitutions are mostly silent and deduced amino acid changes are mainly conservative, suggesting stabilizing selection at the protein level; 2) the three genome segments accumulate mutations at a different rate; 3 ) some of the circulating PUUV variants are frequently observed while others are transient; 4) frequently occurring PUUV variants are composed of the most abundant segment genotypes (copious) and new transient variants are continually generated; 5) reassortment of PUUV genome segments occurs regularly and follows a specific pattern of segments association; 6) prevalence of reassortant variants oscillates with season and is higher in the autumn than in the spring; and 7) reassortants are transient, i.e., they are not competitively superior to their parental variants. Collectively, these observations support a quasi-neutral mode of PUUV microevolution with a steady generation of transient variants, including reassortants, and preservation of a few preferred genotypes.
\end{abstract}

Citation: Razzauti M, Plyusnina A, Henttonen H, Plyusnin A (2013) Microevolution of Puumala hantavirus during a Complete Population Cycle of Its Host, the Bank Vole (Myodes glareolus). PLoS ONE 8(5): e64447. doi:10.1371/journal.pone.0064447

Editor: Dhanasekaran Vijaykrishna, Duke-NUS Gradute Medical School, Singapore

Received April 3, 2012; Accepted April 15, 2013; Published May 22, 2013

Copyright: (c) 2013 Razzauti et al. This is an open-access article distributed under the terms of the Creative Commons Attribution License, which permits unrestricted use, distribution, and reproduction in any medium, provided the original author and source are credited.

Funding: This work has been supported by grants from the Academy of Finland, Sigrid Jusélius Foundation, and was partially funded by EU-FP6 grant GOCE2003-010284 EDEN (http://www.eden-fp6project.net) and the EU grant FP7-261504 EDENext (http://www.edenext.eu) and is catalogued by the EDENext Steering Committee as EDENext021. The contents of this publication are the sole responsibility of the authors and do not necessarily reflect the views of the European Commission. The funders had no role in study design, data collection and analysis, decision to publish, or preparation of the manuscript.

Competing Interests: The authors have declared that no competing interests exist.

*E-mail: maria.razzauti@helsinki.fi

\section{Introduction}

Hantaviruses constitute a distinct genus within the Bunyaviridae [1]. This family is represented by enveloped negative-stranded RNA viruses that possess a tri-segmented genome: the small (S) segment encodes the nucleocapsid $(\mathrm{N})$ protein and, in some hantaviruses, also a non-structural protein $(\mathrm{NSs})$; the medium $(\mathrm{M})$ segment encodes two surface glycoproteins ( $\mathrm{Gn}$ and $\mathrm{Gc}$ ); and the large $(\mathrm{L})$ segment encodes the $\mathrm{L}$ protein, the viral RNA-dependent RNA polymerase [2].

Puumala virus (PUUV) [3] is the main rodent-borne pathogen in Europe, where it causes nephropathia epidemica (NE), a relatively mild form of haemorrhagic fever with renal syndrome [4]. The host of PUUV is the bank vole (Myodes glareolus), a woodland rodent that occurs from the British Isles through continental Europe and Russia to the Lake Baikal [5]. The occurrence of NE depends strongly on the population dynamics of the bank vole; population peaks are mirrored by NE outbreaks with a short time-lag [6-8].

Bank voles are chronically infected by PUUV [9-10]. Viral secretion occurs during half a year after infection [9], [11] and the virus transmission is horizontal, mainly via breathing of aerosolized excreta generated by infected rodents [12-14]. Such indirect mode of transmission and virus survival outside the host promotes viral persistence in the bank vole population [15-16]. Maternal antibodies transferred by infected females to their progeny protect them up to 80 days, and this may shape the dynamics of virus transmission during breeding season and shortly thereafter [1718]. Similar to other RNA viruses, hantaviruses exhibit a high short-term substitution rate. Genetic diversity in hantaviruses is generated by genetic drift (i.e., a gradual accumulation of point mutations throughout the genome coupled with small deletions and insertions within the non-coding regions of the RNA segments [19]) and reassortment of genome segments [19-22]. Evidence for homologous recombination has also been reported [23-24], but this seems to be a rare event [25]. While the vast majority of point mutations observed are silent, reflecting stabilizing selection at the aa level [26], there is some evidence for directional selection [27]. Genetic heterogeneity is comparable among hantaviruses species found in different rodent subfamilies. Nucleotide (nt) diversity among hantavirus species is variable and characterized by the number of strains recognized. Inter-lineage diversity of PUUV may be as high as $38 \%$ for the $\mathrm{S}$ segment, and sequence heterogeneity is unevenly distributed along the genome [28]. Despite the growing database of genome sequences and the increasing number of studies on genetic variability of hantaviruses, none to date have considered the nature of viral genetic diversity 
on a scale of a host population and sampled during several-years period. However, such studies of virus microevolution are essential for a better understanding of the mechanisms shaping hantavirus evolution. Previously [19], we examined PUUV genetic diversity in a bank vole population. This study included 31 distinct viral strains circulating during 2005 in Central Finland. A substantial genetic diversity was observed between circulating PUUV strains. Moreover, phylogenetic analysis of the S, M and L genome sequences clustered the variation into two distinct genogroups. As such, recognition of reassortant strains was straightforward and $20 \%$ of the circulating PUUV strains were found to be carrying inter-genogroup reassortant genomes. This analysis raised several questions concerning temporal fluctuations of the diversity of PUUV strains, how it is influenced by the host population density, and the fate of individual PUUV strains. Here, we expand our earlier study and report the microevolution of PUUV in its host population during a five-year period, covering both peak and decline phases of the bank vole population cycle.

\section{Materials and Methods}

\section{Ethics statement}

According to the Finnish Act on the Use of Animals for Experimental Purposes (62/2006) and a further decision by the Finnish Animal Experiment Board (May 16th, 2007), the techniques employed to capture rodents, i.e., life- and snaptrapping are not considered an animal experiment and therefore requires no animal ethics license from the Finnish Animal Experiment Board. The species captured for this study, Myodes glareolus, neither is protected nor included in the Red List of Finnish Species. Animal trapping took place on private and Finnish national forest by permit (1013/204/2002). Landowners were consulted and the trapping was allowed before the study was conducted.

\section{Sampling of rodents}

Rodents were trapped at Konnevesi, Central Finland $\left(62^{\circ} 34^{\prime} \mathrm{N}\right.$, $26^{\circ} 24^{\prime} \mathrm{E}$ ) twice a year (May and October) from 2005 till 2009. During the early 2000s, bank voles were strongly cyclical in Central Finland [7]; 2005 was a cyclic peak year, 2006 decline and crash, 2007 a strong increase phase, 2008 a high peak, and 2009 another decline. Trapping was done at 38 sites within $120 \mathrm{~km}^{2}$ of typical taiga forest, mainly dominated by Norway spruce (Picea abies), Scots pine (Pinus sylvestris), downy birch (Betula pubescens) and silver birch (Betula pendula). Of 38 trapping sites, 14 were sampled from May 2005 to October 2009 using grids of $3 \times 3$ Ugglan Special live traps (Grahnab, Hillerstorp, Sweden) set $15 \mathrm{~m}$ apart. Traps were set for three nights and checked twice per day to minimize animal stress. From May 2007 onwards, 24 additional trapping sites were added to increase the study material. These consisted of 4 transects of 15 standard snap-traps at $15 \mathrm{~m}$ intervals over two nights. The trapping sites were situated 500 to $1000 \mathrm{~m}$ apart from each other. Bank voles captured alive were anesthetized with isofluarene (Forene, Abbott, UK), bled from the retroorbital sinus and sacrificed by cervical dislocation and immediately frozen. Similarly, snap-trapped bank voles were flash-frozen on dry ice until necropsy. The dissection of rodents was performed in a class II laminar flow hood in a biosafety level 3, animal annotation (weight, sex, maturity, age) was completed and tissue samples were individually deep-frozen until further analyses.

\section{Screening of samples}

All rodents were first screened for the presence of PUUV Nantigen $(\mathrm{Ag})$ using immunoblotting. Briefly, lung tissue samples (approx. $20 \mathrm{mg}$ ) in $500 \mu \mathrm{l}$ of Laemmli buffer were incubated at room temperature overnight, then homogenized by sonication and heated to $80-100^{\circ} \mathrm{C}$ for 5 minutes. Aliquots of $25 \mu \mathrm{l}$ were separated by electrophoresis in $10 \%$ sodium dodecyl sulphate polyacrylamide gels and proteins were subsequently transferred onto nitrocellulose membranes. To verify the blotting efficacy, membranes were stained with $1 \times$ Ponceau S staining solution for 1 minute and destained in distilled water until the background was clear. Membranes were blocked with $1 \%$ bovine serum albumin solution overnight at $+4^{\circ} \mathrm{C}$. Membranes were incubated with rabbit polyclonal antiserum made against recombinant $\mathrm{N}-\mathrm{Ag}$ for two hours at room temperature, washed with $0.1 \%$ Ten-Tween 20 solution, and incubated for one hour with Odyssey IRDye 800CW goat anti-rabbit secondary $\mathrm{Ab}$ (LI-COR), diluted at 1:10000 in PBS. Odyssey Infrared Imaging system was used to detect blotted proteins.

\section{RT-PCR and sequencing of the PUUV genome}

Viral RNA was extracted from lung tissue samples of the N-Agpositive bank voles using the TRIsure reagent (Bioline, UK) according to the manufacturer's instructions. Reverse transcription was performed with RevertAid ${ }^{\mathrm{TM}} \mathrm{H}$ Minus M-MuLV Reverse Transcriptase (Fermentas, Lithuania) and AmpliTaq ${ }^{\circledR}$ DNA polymerase (Applied Biosystems, Foster City, CA, USA) was used to amplify viral cDNA. PUUV S- (nt 631-1085), M- (nt 21622613) and L-segment (nt 505-1040) sequences were amplified as described earlier [19]. PCR amplicons were purified with ExoSAP-IT $^{\mathrm{TM}}$ PCR clean-up reagent (USB Corporation, Miles Road, Cleveland, USA). Automated sequencing was performed using the ABI PRISM ${ }^{\text {TM }}$ Dye Terminator sequencing kit (Perkin Elmer/ABI). Newly recovered S-, M- and L-segment sequences (455, 452 and $536 \mathrm{nt}$ in length respectively) were deposited in GenBank under accession numbers JQ319161-JQ319319.

\section{Genetic variation and phylogenetic analysis}

Nucleotide sequence alignments were generated with BioEdit v7.0.9 [29]. Genetic distances were estimated within and between viral populations with DnaSP [30]. PHYLIP program package [31] was employed to estimate phylogeny of the PUUV sequences. Genetic distances were calculated with the F84 substitution model (Dnadist) and bootstrap supports were obtained generating 1000 replicates of the datasets (Seqboot) and for the reconstruction of PUUV phylogenies the Neighbour-joining (NJ) algorithm (Neighbor) was used. Sequence alignments were submitted to phylogenetic Network 4.600 software (Fluxus-Engineering) to generate genetic and evolutionary relationships among the segment genotypes using Median-Joining algorithm [32]. An examination of recombination among complete sequences was performed using the recombination detection program (RDP) [33] and SimPlot v3.5.1 [34].

\section{Results}

PUUV prevalence and genetic diversity in the bank vole population at Konnevesi

The incidence of PUUV infection and genetic variation of the virus were monitored through a complete bank vole population cycle at Konnevesi from May 2005 until October 2009. The study period covered two peak-phases in 2005 and 2008, and two population declines in 2006 and 2009 (presumably followed by virus bottlenecks). A total of 1369 bank voles were captured, of which 360 (26.3\%) were PUUV-N-Ag-positive. PUUV prevalence at Konnevesi was higher in spring (a mean of 39\%) when most 
Table 1. Number of bank voles captured during the study, PUUV prevalence and proportions of A and B genogroups and reassortants at Konnevesi.

\begin{tabular}{|c|c|c|c|c|c|c|c|c|c|c|}
\hline & May & Oct. & May + Oct. & May & Oct. & May & Oct. & May & Oct. & Total \\
\hline & \multicolumn{2}{|l|}{2005} & 2006 & \multicolumn{2}{|l|}{2007} & \multicolumn{2}{|l|}{2008} & \multicolumn{2}{|l|}{2009} & \\
\hline $\begin{array}{l}\text { no. of trapped } \\
\text { bank voles }\end{array}$ & 47 & 100 & 8 & 54 & 132 & 237 & 625 & 78 & 88 & 1369 \\
\hline no. of PUUV+ & 22 & 22 & 0 & 7 & 15 & 106 & 155 & 28 & 5 & 360 \\
\hline (\%) & $(46.8)$ & $(22)$ & & (13) & (11.4) & $(44.7)$ & $(24.8)$ & (35.9) & $(5.7)$ & (26.3) \\
\hline $\begin{array}{l}\text { no. of variants } \\
\text { of genogroup A }\end{array}$ & 5 & 4 & 0 & 2 & 5 & 40 & 51 & 13 & 5 & 125 \\
\hline (\%) & $(27.8)$ & $(18.2)$ & & $(28.6)$ & (33.3) & $(37.7)$ & $(32.9)$ & $(46.4)$ & $(100)$ & $(35.1)$ \\
\hline $\begin{array}{l}\text { no. of variants } \\
\text { of genogroup B }\end{array}$ & 10 & 13 & 0 & 4 & 7 & 53 & 67 & 9 & 0 & 163 \\
\hline (\%) & $(55.6)$ & $(59.1)$ & & $(57.1)$ & $(46.7)$ & $(50)$ & $(43.2)$ & $(32.1)$ & & $(45.8)$ \\
\hline $\begin{array}{l}\text { no. of Reassortant } \\
\text { variants }\end{array}$ & 3 & 5 & 0 & 1 & 3 & 13 & 37 & 6 & 0 & 68 \\
\hline (\%) & $(16.7)$ & $(22.7)$ & & (14.3) & (20) & $(12.3)$ & (23.9) & (21.4) & & (19.1) \\
\hline
\end{tabular}

doi:10.1371/journal.pone.0064484.t001

voles in the population have over-wintered rather than in autumn $(20.7 \%)$ when younger animals dominate (Table 1$)$.

Partial genome sequences were recovered from 356 PUUV NAg-positive bank voles: $455 \mathrm{nt}$ for the $\mathrm{S}$ segment, $452 \mathrm{nt}$ for the $\mathrm{M}$ segment and $536 \mathrm{nt}$ for the L segment. Direct sequencing of PCRproducts was employed; this way the master sequences were recovered and the "noise" of quasispecies ignored. Taken together, partial S-, M- and L-sequences (a total of $1443 \mathrm{nt}$ ) represented $12 \%$ of the PUUV genome. Of 356 PUUV genomes, $\mathrm{M}$-segment sequences were recovered for 353 genomes (interestingly, all the remaining were reassortant). Pairwise sequence analysis revealed $182 \mathrm{nt}$ differences in the segments analyzed: 53 mutations in the S, 50 in the $\mathrm{M}$, and 79 in the L. The majority of mutations were silent and occasionally non-synonymous substitutions were encountered (Table 2). Numerous genetic markers were found along the studied segments: 10 for the S (T699C, T750C, T789A, A810G, G843A, T876C, G936A, T945C, C1014T, T1044C), 7 for the M (C2180T, C2207T, A2216G, G2471A, A2483G, G2543A, C2567T) and 29 for the L (G514T, G523A, T532C, C538T, G656A, C593T, G601A, G679A, G682T, A742G, A754G, G769A, C829T, A832G, T838C, G904A, T910C, G916A, A922G, C928T, A964T, C967T, A982T/G, A988T/C, A1003G, A1006G, C1009T, T1025C, G1034T) (Table 2). Such genetic markers allowed the recognition and discrimination of two genogroups (i.e., genetically related strains within a virus lineage) referred as " $\mathrm{A}$ " and " $\mathrm{B}$ " and represented in the figures in red and blue colors respectively. These groups were also inferred from phylogenetic analyses of sequence data (Fig. 1).

Genetic diversity of PUUV segments within genogroups was similar for all segments (1.5-3.2\%). Inter-genogroup diversity varied from 4.8 to $10.1 \%$; surprisingly, the highest values were attributed to the $\mathrm{L}$ segment. Furthermore, a non-synonymous substitution was found in the $\mathrm{L}$ protein that could be used as a molecular marker for genogrouping; in the genogroup $\mathrm{A}$, the aa residue at position 83 was isoleucine while in the genogroup B this residue was valine (Table 2).

\section{Genotyping of Konnevesi PUUV strains}

Genetic diversity of circulating PUUV strains was evaluated, and the number of circulating genotypes (i.e., genetically unique representatives of each of the virus segments) estimated. A total of 45 S-segment genotypes, $38 \mathrm{M}$-segment genotypes and $61 \mathrm{~L}$ segment genotypes were recognized. Genogroup A included 11 S-, $18 \mathrm{M}$-, and $26 \mathrm{~L}$-segment genotypes referred respectively as S1A to S11A, M1A to M18A and L1A to L26A. Corresponding numbers for genogroup B were 34, 20 and 35 and respectively referred as S1B to S34B, M1B to M20A and L1B to L35B (Table 2 and Fig. 1). Variants of genogroup $B$ were generally more abundant and diverse (Table 1 and Fig. 2). The 356 PUUV sequences comprised 184 distinct genetic variants. Of those, 46 belonged to genogroup $A\left(A_{S} A_{M} A_{L}\right), 82$ to genogroup $B$ $\left(\mathrm{B}_{\mathrm{S}} \mathrm{B}_{\mathrm{M}} \mathrm{B}_{\mathrm{L}}\right)$, and 56 were reassortants between these groups (Fig. 1E). Interestingly, only 39 of these 184 distinct variants were found repeatedly over the observation period; other variants were registered only once (Table 3). No accumulation of certain variants at the given geographic sites was observed. Neither substantial deviation in diversity between sites nor any bias linked to the terrain topology was registered.

An independent analysis of each segment of PUUV genomes allowed the distinction of the most abundant genotypes (from here on referred to as "copious"): $6 \mathrm{~A}, 7 \mathrm{~A}, 8 \mathrm{~A}, 5 \mathrm{~B}, 20 \mathrm{~B}, 21 \mathrm{~B}, 22 \mathrm{~B}$ and $28 \mathrm{~B}$ for the S segment; 1A, 8A, 14A, 15A, 3B, 8B and 15B for the M segment; and 3A, 9A, 14A, 4B, 8B, 11B, 19B, 21B and 23B for the $\mathrm{L}$ segment. Figure 2 shows the frequency of occurrence of the segment genotypes as well as their relationships. Clusters of several genotypes can be seen for the $\mathrm{S}$ and $\mathrm{M}$ segments of both genogroups. These clusters consist of at least one copious genotype and several genotypes that were seldom observed (from here on referred to as "sporadic"). For example, the copious S genotype 28B and sporadic genotypes 27B, 30B, 31B, 32B, 33B, 34B form such a cluster. Differently, the $\mathrm{L}$ segment was represented by more genotypes, probably reflecting a higher nt substitutions rate in this segment. Thus high number of drifted nt resulted in abundant genetically-related variants illustrated in interconnected circles of a smaller size in the graphical representation of the segment genotypes (Fig. 2). 

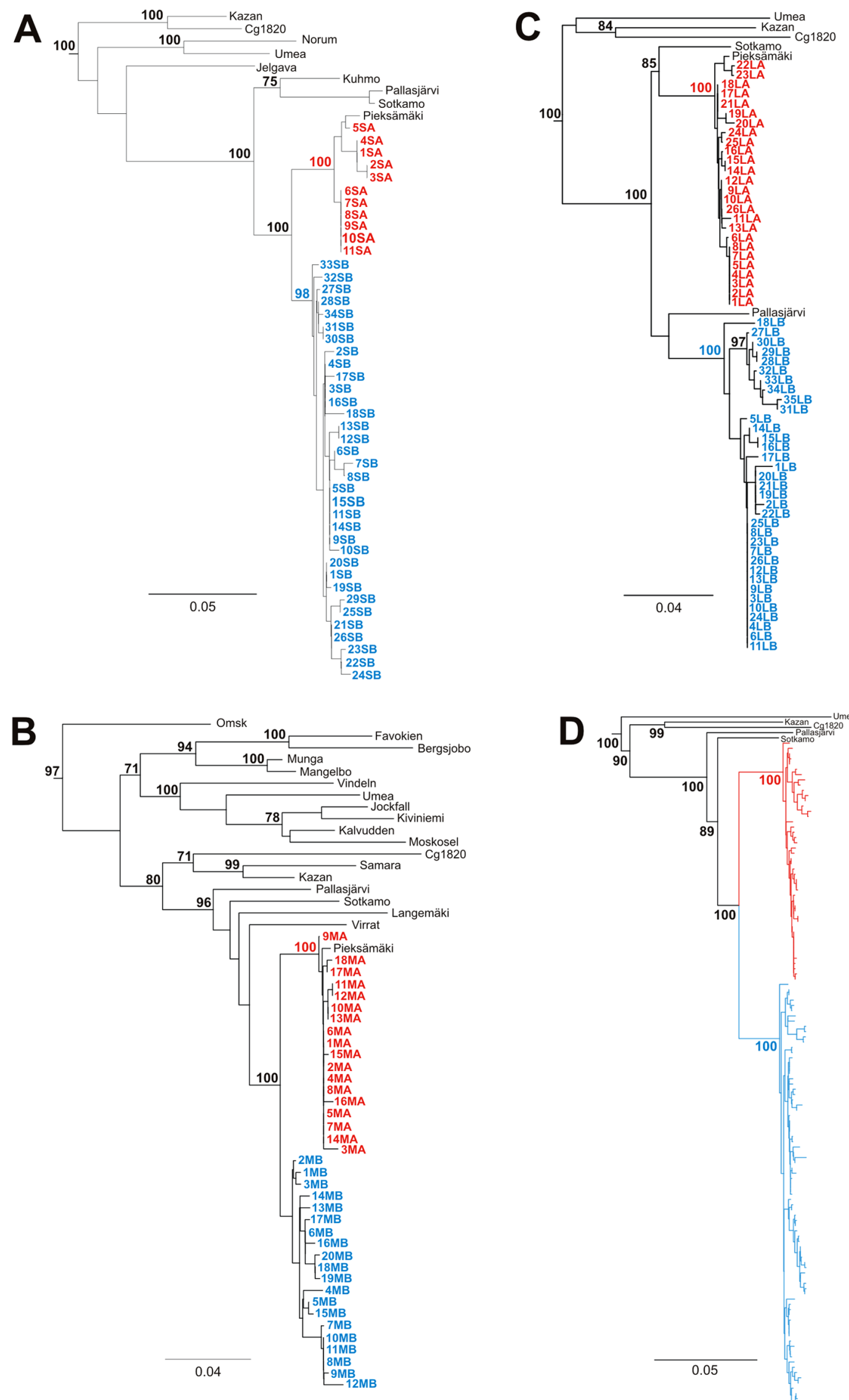

E

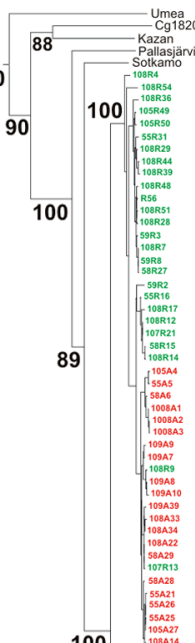

D

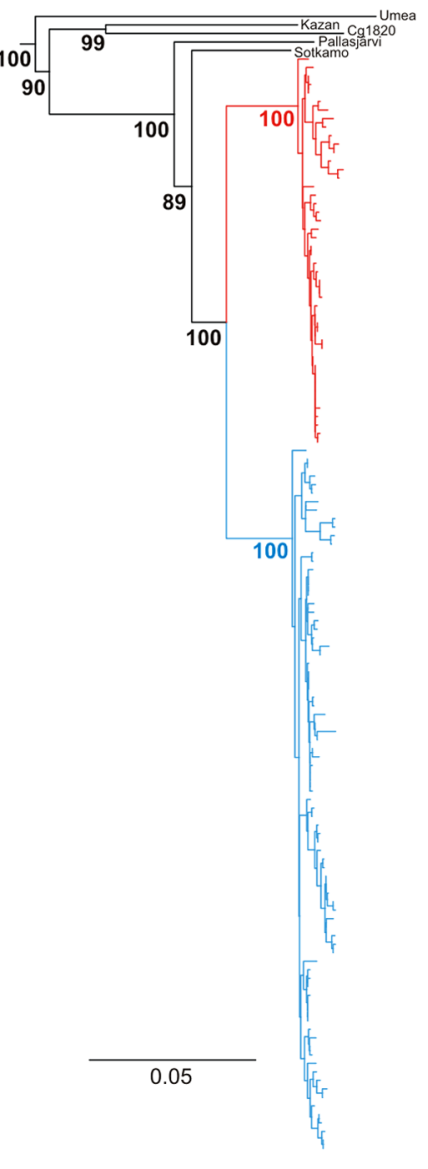

0.05 
Figure 1. Phylogenetic trees. Phylogenetic trees (Neighbor-Joining) calculated for the $S, M$ and $L$ segment sequences of PUUV, and contings of the three segment sequences: (A) partial S (nt 631-1085); (B) partial M (nt 2162-2613); (C) partial L (nt 505-1040); (D) a contig of the three genome segments omitting reassortant variants, and $(E)$ a contig of the three genome segments including reassortant variants. A maximum clade credibility tree with an arbitrary root is shown with mean branch lengths (substitutions per site), and non-parametric bootstrap percentages are shown for each node. DOBV, ANDV, SNV and TULV were used as outgroups and omitted for the graphical representation.

doi:10.1371/journal.pone.0064447.g001

\section{Dynamics of PUUV variants during a bank vole population cycle}

Relatively large collection of PUUV sequences recovered over a 5 -year period gave a unique opportunity to follow individual genetic variants of the virus through phases of high and low population density. Analysis of segment genotypes dynamics revealed that the copious genotypes were prevalent throughout the observation window whereas most of sporadic genotypes were transient, only a few of them were observed on more than one occasion. New genotypes were continually detected during the study, except in 2006 when no PUUV-infected voles were found (Fig. 3). In other words, the PUUV genes pool was unique at every time-point. Table 4 shows variants that have derived from one or a few nt substitutions, reflecting the contribution of genetic drift to PUUV diversity. Importantly, no evidence for a founder effect (the loss of genetic variation that occurs when a subpopulation of a small number of individuals is established [35]) was observed for the segment genotypes after a decline in the bank vole population (presumably a virus bottleneck). To analyze PUUV strains dynamics, we classified circulating variants into four categories: (i) the most frequently occurring variants, each detected five or more times; (ii) repeatedly observed variants, detected 2-4 times; (iii) transient variants, detected only once; and (iv) reassortant variants, which were analyzed separately due to their peculiar genetic nature (Table 5). The most frequently occurring variants ( $\geq 5$ times) included only copious genotypes for each genome segment. Two of these variants were clearly dominant: $A 13$ was observed 53 times from May 2007 to October 2009, and B3 was observed 21 times from October 2007 to October 2008.
Repeatedly observed variants (2-4 times) were detected at no more than two study points (Table 4). Of those repeatedly observed variants, $74 \%$ of $\mathrm{S}$ segments, $67 \%$ of $\mathrm{M}$ segments and approx. 30\% of L segments were of copious genotypes. For the transient variants (1 time), all three segments were represented by copious and sporadic segment genotypes in approximately equal proportions.

\section{Reassortant variants}

Co-circulation of two distinct genogroups of PUUV allowed for straightforward recognition and subsequent study of reassortants variants. In total, 68 of $356(19.1 \%)$ PUUV genomes were found to be reassortant. They were represented by 56 distinct variants and only three of those were observed more than once throughout the study period (Table 3). All six possible combinations of PUUV genome segments were found among reassortant strains and, interestingly, a certain pattern of segment combination was observed. In the vast majority of cases $(95.6 \%)$ only the $\mathrm{S}$ or $\mathrm{M}$ segments were exchanged (Table 6). In other words, the L segment preferably remained paired with S- or M-segments of the same genogroup. Reassortant variants consisted of copious S- and Msegment genotypes in $75 \%$ and $66 \%$ of cases respectively, whereas the $\mathrm{L}$ genome segment was equally composed of copious and sporadic genotypes (Table 4). The composition of copious and sporadic genotypes was similar for both repeatedly observed and reassortant variants. However, the repeatedly observed variants could be seen at two different time-points, while reassortants were transient with the exception of three variants detailed in Table 5. The proportion of reassortants in the viral population varied from spring to autumn and was inversely related to PUUV prevalence, i.e. was

Table 2. Genetic diversity of PUUV variants at Konnevesi.

\begin{tabular}{|c|c|c|c|c|}
\hline Genome segment & & $\mathbf{S}$ & M & $\mathbf{L}$ \\
\hline \multirow[t]{2}{*}{ Length } & $\mathrm{nt}$ & 455 & 452 & 536 \\
\hline & aa & 151 & 150 & 178 \\
\hline \multirow[t]{3}{*}{ no. of nt substitutions } & Groups $\mathbf{A}$ and $\mathbf{B}$ & 53 & 50 & 79 \\
\hline & Within group A & 17 & 16 & 24 \\
\hline & Within group B & 33 & 32 & 38 \\
\hline \multirow[t]{3}{*}{ Genetic diversity (\%) } & Groups $\mathbf{A}$ and $\mathbf{B}$ & 6.2 & 4.8 & 10.1 \\
\hline & Within group A & 2.5 & 1.6 & 1.5 \\
\hline & Within group B & 2.5 & 2.7 & 3.2 \\
\hline \multirow[t]{3}{*}{ no. of aa substitutions } & Between groups $\mathbf{A}$ and $\mathbf{B}$ & - & - & 1 (A I83V B) \\
\hline & Within group A & 3 (K41R, M75I, D79E) & 3 (S11N, E43K, C109G) & 3 (143V, N93I, N168K) \\
\hline & Within group B & $\begin{array}{l}9 \text { (F31I, V33E, R39K, P57S, } \\
\text { Q78P, D79N, A87V, A97S, } \\
\text { Q144P) }\end{array}$ & 4 (P71L, S92P, S101A, I110V) & $\begin{array}{l}8 \text { (T7S, D46E, R67C, N86D, } \\
\text { R116K, T121I, S141G, V165I) }\end{array}$ \\
\hline \multirow[t]{3}{*}{ no. of genotypes } & Total & 45 & 38 & 61 \\
\hline & Within group A & 11 & 18 & 26 \\
\hline & Within groups B & 34 & 20 & 35 \\
\hline $\begin{array}{l}\text { no. of genogroup } \\
\text { discriminative markers }\end{array}$ & Between groups $\mathbf{A}$ and $\mathbf{B}$ & 10 & 7 & 29 \\
\hline
\end{tabular}


A

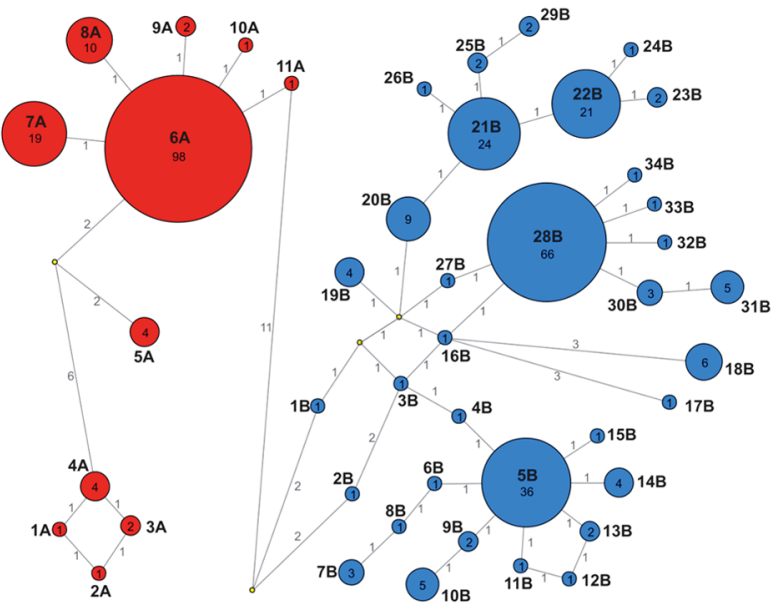

B
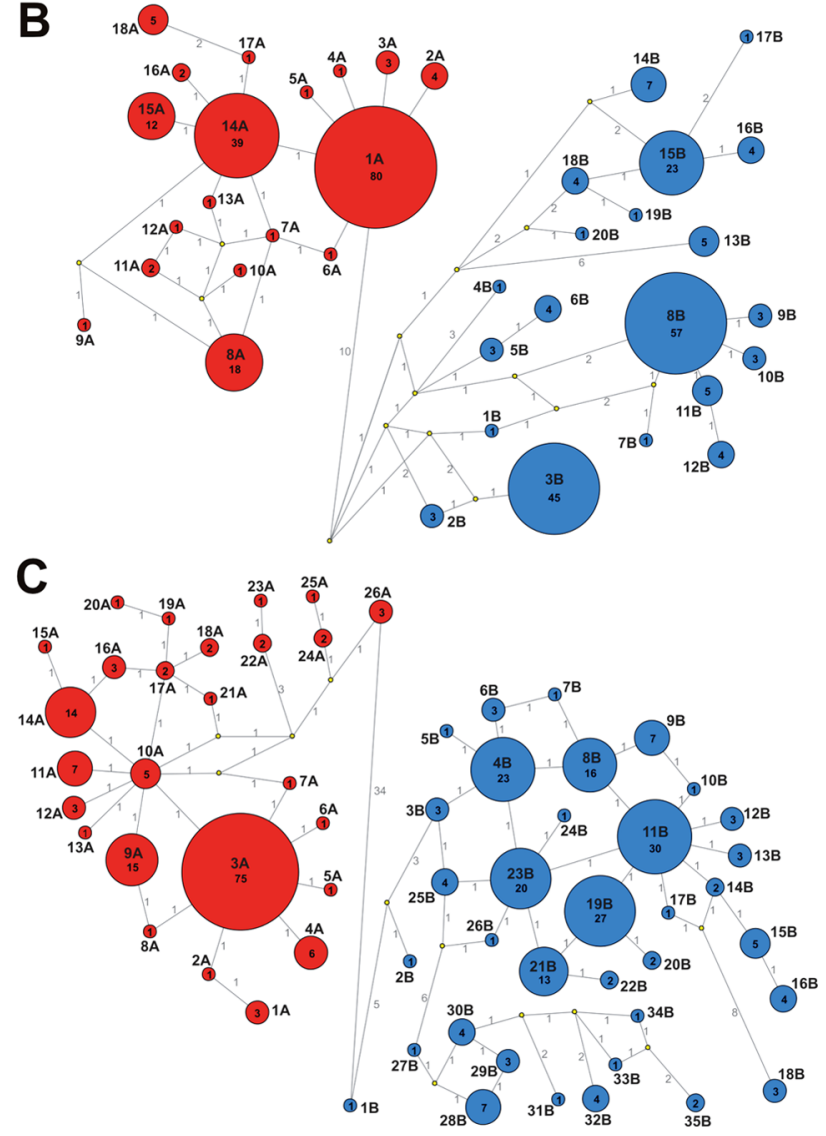

Figure 2. Genetic relationships between (A) S-segment, (B) Msegment and (C) L-segment genotypes. Relationships were constructed using Network analysis and the MJ algorithm. Genotypes of group A are represented by red circles and genotypes of group B by blue circles. The size of the circle is proportional to the number of representatives of each genotype; and numbers are shown inside. Yellow circles are median vectors suggested by Network. The numbers on the link-lines show the number of mutations between genotypes; the length of link-lines is not proportional to the number of mutations.

doi:10.1371/journal.pone.0064447.g002

higher in autumn when the prevalence is lower, and lower in spring when the prevalence is higher (Table 1). These oscillations were not observed for parental variants.
Table 3. Genetic variants of PUUV observed in the Konnevesi bank vole population.

\begin{tabular}{lllll}
\hline & Group A & Group B & Reassortant & Total \\
\hline & 125 & 163 & 68 & 356 \\
\hline $\begin{array}{l}\text { Total no. of observed } \\
\text { PUUV genomes }\end{array}$ & & & & \\
$\begin{array}{l}\text { Total no. of PUUV } \\
\text { genetic variants }\end{array}$ & 46 & 82 & 56 & 184 \\
$\begin{array}{l}\text { no. of variants } \\
\text { observed more than } \\
\text { once (\%) }\end{array}$ & $14(30.4)$ & $22(26.8)$ & $3(5.4)$ & $39(21.2)$ \\
$\begin{array}{l}\text { no. of transient } \\
\text { variants (\%) }\end{array}$ & $32(69.6)$ & $60(73.2)$ & $53(94.6)$ & $145(78.8)$ \\
\hline $\begin{array}{l}\text { doi:10.1371/journal.pone.0064447.t003 } \\
\text { dint }\end{array}$ & & & & \\
\hline
\end{tabular}

\section{Double infections}

A prerequisite for PUUV reassortment is the coexistence of two viral genomes in the same host, i.e. a double infection. Visual inspection of sequence chromatograms revealed double peaks at the diagnostic positions for genogroups in twelve sequences: six for the $\mathrm{S}$ segment, two for the $\mathrm{M}$ segment and four for the $\mathrm{L}$ segment. Double peaks were distributed not randomly along the sequences but appeared exclusively at the genotype-specific positions. Hence, such double peaks cannot result from simultaneous nt substitution at given positions reflect a double-infection. Detected double infections with two genotypes were not observed circulating as reassortant variants. Sequencing of individual cDNA clones showed the presence of two strains of the virus (one of each genogroup) and hence confirmed a double infection in the host. Interestingly, all but one sequence with double peaks were recovered from samples collected in October when conditions for double infections seem to be higher (see Discussion).

To search for traces of recombination in PUUV genomes circulating at Konnevesi, four variants, two of each genogroup (A and $\mathrm{B}$ ), were selected and their complete $\mathrm{S}$ and $\mathrm{M}$ segment sequences and approx. $80 \%$ of the $\mathrm{L}$ segment sequence were recovered and analysed. No apparent signs of recombination were observed. Although this result does not completely exclude the possibility of recombination, it suggests that recombination occurs much less frequently than reassortment. An alternative explanation could be that recombinant viruses, even if generated frequently, may not be able to replicate as efficiently as parental viruses or reassortants.

\section{Discussion}

For the first time, the microevolution of PUUV has been studied throughout the host population cycle. The data set analyzed here (1369 bank voles of which 360 were PUUV infected) was indeed larger than in our preceding study [19], in which 147 bank voles captured in 2005 and 40 PUUV genomes were analyzed. The present results support and expand our earlier conclusions concerning PUUV genetic diversity and the frequency of segment reassortment. In addition, the five-year monitoring of PUUV genomes allowed the study of PUUV microevolution, particularly, to follow the fate of individual genetic variants, including reassortants.

Of 1369 bank voles captured, 360 were found infected and 356 PUUV genome sequences were successfully recovered. Although not statistically significant, PUUV prevalence tend to be higher in the spring when most bank voles were mature and had overwintered, than in the autumn when animals born the summer 


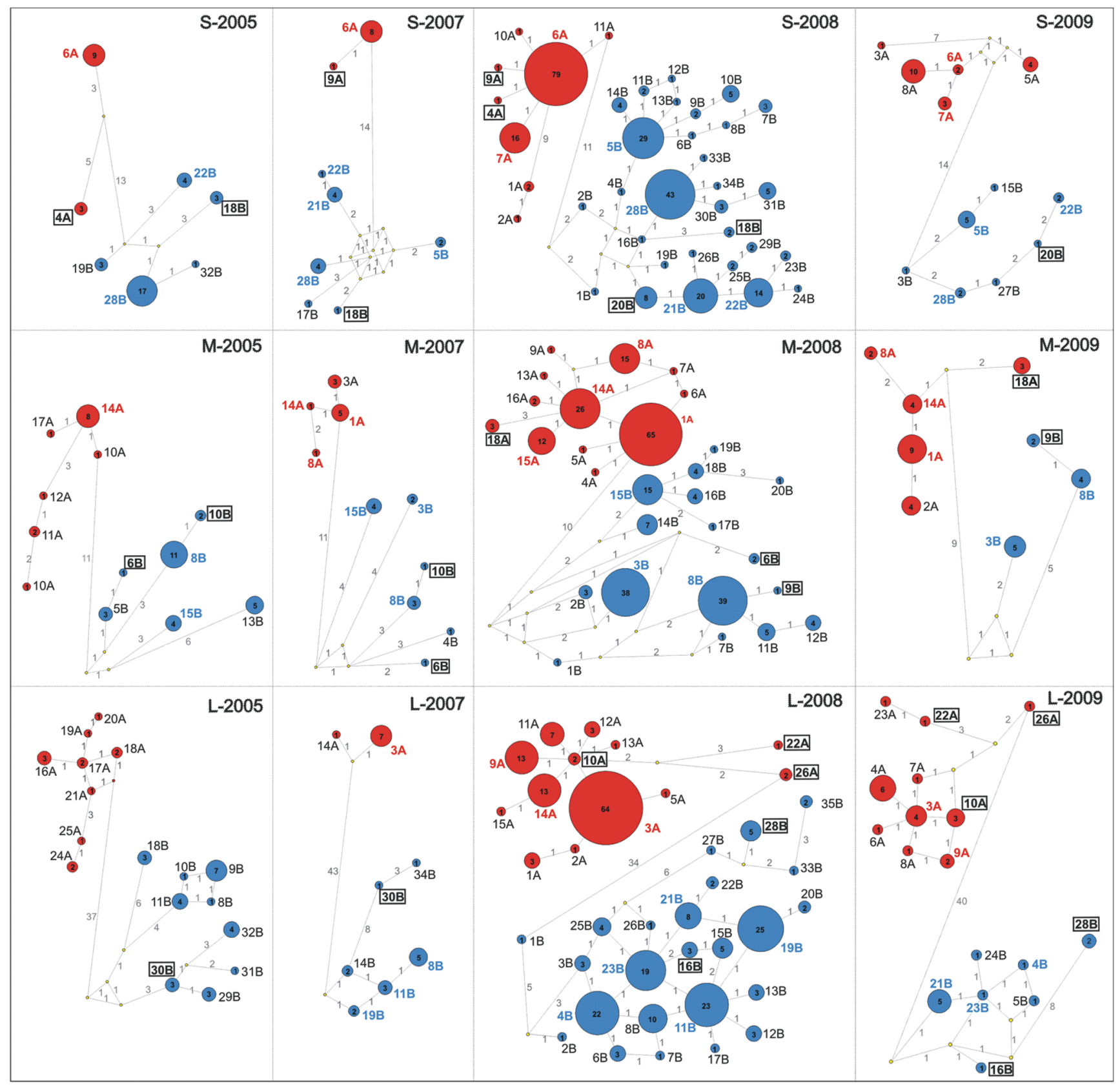

Figure 3. PUUV segment genotypes circulating in the bank vole population at Konnevesi from 2005 to 2009. Relationships between S-, M- and L-segment genotypes was constructed using Network. Genotypes of group A are represented by red circles and genotypes of group B by blue circles. The size of the circles is proportional to the number of representatives of each genotype; and numbers are shown inside. Most abundant circulating genotypes (copious) are designated in red and blue, for the A and B genogroups, respectively. Sporadic genotypes, detected only once, are shown in black and sporadic genotypes observed through several seasons are shown in a square. Yellow circles are median vectors suggested by Network. The numbers on the link-lines show the number of mutations between genotypes; the length of link-lines is not proportional to the number of mutations. Note that the trapping effort was increased from 2007 thus numbers from 2005 are not directly comparable to those of 2007-09. doi:10.1371/journal.pone.0064447.g003

before predominate (Table 1). This observation is in concordance with other studies on PUUV prevalence [18], [36-37].

Earlier analyses of circulating PUUV in the same host population at Konnevesi revealed two distinct genogroups, A and $\mathrm{B}$ [19]. Both genogroups were present in the viral population along the monitoring period with a sole exception; no variants of the group B were detected in October 2009 (Table 1 and Fig. 3). It cannot be clarified here if this is a reflection of the low numbers of that sample set or that genogroup suddenly disappear. Genogroup B was generally more abundant and diverse (Table 1 and Fig. 3). The ratio of circulating $\mathrm{A}$ and $\mathrm{B}$ variants was relatively stable through the host density cycle, except during the decline phases in 2006 and 2009 (Table 1), and no clear signs of competition between genogroups were detected during the study. To our knowledge, competition between hantavirus variants has only been 
Table 4. PUUV variants repeatedly detected in the bank vole population.

\begin{tabular}{|c|c|c|c|c|c|c|}
\hline \multirow[t]{2}{*}{ no. of representatives } & \multirow[t]{2}{*}{ variant } & \multicolumn{3}{|c|}{ Genotypes } & \multirow[t]{2}{*}{ no. of trapping sites } & \multirow[t]{2}{*}{ trapping seasons } \\
\hline & & $\mathbf{S}$ & $\mathbf{M}$ & $\mathbf{L}$ & & \\
\hline 2 & $A 4$ & 4 & 11 & 24 & 1 & $5 / 05 ; 10 / 05$ \\
\hline 3 & $A 11$ & $\underline{6}$ & $\underline{1}$ & 1 & 2 & $10 / 08$ \\
\hline 53 & A13 & $\underline{6}$ & 1 & $\underline{3}$ & 17 & $5 / 07 ; 10 / 07 ; 5 / 08 ; 10 / 08 ; 5 / 09$ \\
\hline 2 & A16 & $\underline{6}$ & $\underline{1}$ & 10 & 2 & $5 / 08 ; 10 / 08$ \\
\hline 2 & $A 24$ & $\underline{6}$ & $\underline{14}$ & $\underline{14}$ & 2 & $5 / 08 ; 10 / 08$ \\
\hline 2 & $A 25$ & $\underline{6}$ & $\underline{14}$ & 16 & 2 & $5 / 05 ; 10 / 05$ \\
\hline 2 & A27 & $\underline{6}$ & $\underline{14}$ & 18 & 1 & $10 / 05$ \\
\hline 2 & $A 29$ & $\underline{6}$ & 15 & $\underline{9}$ & 2 & $5 / 08$ \\
\hline 5 & A30 & $\underline{6}$ & $\underline{15}$ & $\underline{14}$ & 4 & $5 / 08 ; 10 / 08$ \\
\hline 8 & A34 & $\underline{7}$ & $\underline{14}$ & $\underline{9}$ & 2 & $5 / 08 ; 10 / 08$ \\
\hline 4 & A36 & $\underline{7}$ & $\underline{14}$ & 11 & 2 & $5 / 08 ; 10 / 08$ \\
\hline 2 & $A 40$ & $\underline{8}$ & $\underline{1}$ & $\underline{3}$ & 1 & $5 / 09$ \\
\hline 4 & $A 41$ & $\underline{8}$ & $\underline{1}$ & 4 & 1 & $5 / 09$ \\
\hline 2 & $A 43$ & 8 & 2 & 4 & 1 & $5 / 09$ \\
\hline 2 & $B 22$ & 14 & $\underline{3}$ & $\underline{19}$ & 1 & $10 / 08$ \\
\hline 21 & $B 3$ & $\underline{5}$ & $\underline{3}$ & $\underline{19}$ & 7 & $10 / 07 ; 5 / 08 ; 10 / 08$ \\
\hline 6 & B5 & $\underline{\mathbf{5}}$ & $\underline{3}$ & $\underline{21}$ & 5 & $10 / 08 ; 5 / 09$ \\
\hline 2 & B8 & 7 & $\underline{3}$ & $\underline{21}$ & 1 & $10 / 08$ \\
\hline 2 & $B 28$ & 18 & 6 & 35 & 1 & $5 / 08$ \\
\hline 3 & B34 & 20 & 14 & 15 & 1 & $5 / 08$ \\
\hline 2 & B35 & 20 & 14 & 16 & 2 & $10 / 08$ \\
\hline 5 & B39 & $\underline{21}$ & $\underline{15}$ & $\underline{11}$ & 4 & $10 / 07 ; 5 / 08$ \\
\hline 2 & $B 40$ & $\underline{21}$ & $\underline{15}$ & 14 & 1 & $5 / 07$ \\
\hline 6 & $B 42$ & $\underline{21}$ & $\underline{15}$ & $\underline{23}$ & 2 & $10 / 08$ \\
\hline 3 & $B 48$ & $\underline{22}$ & $\underline{15}$ & 29 & 3 & $5 / 05$ \\
\hline 3 & B59 & $\underline{28}$ & 8 & 3 & 1 & $10 / 08$ \\
\hline 10 & $B 60$ & $\underline{28}$ & $\underline{8}$ & $\underline{4}$ & 5 & $10 / 08 ; 5 / 09$ \\
\hline 3 & $B 73$ & $\underline{28}$ & 11 & $\underline{4}$ & 2 & $10 / 08$ \\
\hline 4 & $B 78$ & 31 & 12 & $\underline{4}$ & 2 & $10 / 08$ \\
\hline 2 & $B 62$ & $\underline{28}$ & $\underline{8}$ & 6 & 1 & 10/08 \\
\hline 12 & $B 64$ & $\underline{28}$ & 8 & 8 & 5 & 10/07; 5/08 \\
\hline 4 & $B 65$ & $\underline{28}$ & $\underline{8}$ & 9 & 2 & $10 / 05$ \\
\hline 2 & $B 67$ & $\underline{28}$ & $\underline{8}$ & $\underline{11}$ & 2 & $5 / 05 ; 10 / 05$ \\
\hline 2 & B57 & $\underline{28}$ & 5 & 18 & 1 & $5 / 05$ \\
\hline 4 & $B 68$ & $\underline{28}$ & 8 & 28 & 2 & $10 / 08$ \\
\hline 2 & $B 72$ & $\underline{28}$ & 10 & 30 & 1 & $10 / 05$ \\
\hline 7 & $R 40$ & $\underline{22}$ & $\underline{8}$ & $\underline{11}$ & 2 & $5 / 07 ; 5 / 08$ \\
\hline 4 & $R 42$ & $\underline{22}$ & 8 & $\underline{23}$ & 2 & $10 / 08 ; 5 / 09$ \\
\hline 4 & $R 51$ & $\underline{28}$ & 15 & $\underline{14}$ & 2 & $10 / 08$ \\
\hline
\end{tabular}

Most abundant (copious) segment genotypes are in bold and underlined. Shadowed blocks contain variants that might have derived from $1-2$ point mutations in one or two segments (e.g., strains $A 13$ and $A 16$ could have originated by accumulating one or two mutations, respectively, in the L segment of $A 11$ strains).

doi:10.1371/journal.pone.0064447.t004

studied in cell culture [38-39] and corresponding data for other RNA viruses are limited (e.g. [40]).

The PUUV population was composed of several segment genotypes, L genotypes being more numerous than $\mathrm{S}$ or $\mathrm{M}$ genotypes. The range of genetic diversity within each genogroup was comparable for all three segments and, for the $\mathrm{S}$ and $\mathrm{M}$ segments also the inter-genogroup diversity was similar. In contrast, L-segment sequences showed surprisingly high diversity between the two genogroups (Table 2). It should be emphasized that the variability of the $\mathrm{L}$ segment region selected for our analysis (nt 505-1040) is typical of the segment among PUUV strains. Therefore, a likely explanation for the high inter-genogroup diversity of $\mathrm{L}$ segment could involve an independent evolutionary history of those genome segments of the Konnevesi strains. 
Table 5. Proportion of copious segment genotypes that composed the PUUV variants detected during the five-year study period.

\begin{tabular}{|c|c|c|c|c|c|}
\hline Variants & Genogroup & no. of variants & $\begin{array}{l}\text { \% of copious } \\
\text { genotypes of S }\end{array}$ & $\begin{array}{l}\% \text { of copious } \\
\text { genotypes of } M\end{array}$ & $\begin{array}{l}\% \text { of copious } \\
\text { genotypes of } \mathrm{L}\end{array}$ \\
\hline \multirow{2}{*}{$\begin{array}{l}\text { The most frequently } \\
\text { occurring ( } \geq 5 \text { times) }\end{array}$} & A & 3 & 100 & 100 & 100 \\
\hline & B & 6 & & & \\
\hline \multirow{2}{*}{$\begin{array}{l}\text { Repeatedly observed (2-4 } \\
\text { times) }\end{array}$} & A & 11 & 74.1 & 66.7 & 29.6 \\
\hline & B & 16 & & & \\
\hline \multirow[t]{2}{*}{ Transient ( = 1 time) } & A & 32 & 44.6 & 58.7 & 50 \\
\hline & B & 60 & & & \\
\hline Reassortant & & 56 & 75 & 66.1 & 53.6 \\
\hline
\end{tabular}

doi:10.1371/journal.pone.0064447.t005

Phylogenetic analysis supported this hypothesis: the L sequences of genogroup A shared a MRCA with PUUV Sotkamo strain while genogroup B shared the MCRA with PUUV Pallasjärvi strain, both strains (i.e., certain genetic variant of a virus species) belong to the Finnish genetic lineage (Fig. 1A-G). Different evolutionary histories for PUUV genome segments were earlier suggested to account for observed variation in the Alpe-Adrian [41] and Latvian [42] lineages. Incidentally, $60 \mathrm{~km}$ south-east of the Konnevesi study area, at Pieksämäki, only variants of genogroup A were observed [43]. Whether this is a consequence of competition between $\mathrm{A}$ and $\mathrm{B}$ variants or peculiarity of their geographical distribution remains unclear. Extended monitoring of the PUUV variants in circulation is required to clarify this issue.

In Finland, PUUV prevalence fluctuates seasonally. However, this study shows that genetic composition of the viral population is not dependent of such seasonality. At each sampling point the PUUV population was roughly renewed; some genetic variants (i.e., sets of three genome segments) were observed persisting throughout the study but a large number were observed only temporarily (Table 3). In contrast, many of the segment genotypes were detected throughout the entire study period (Fig. 3). In other words, the survival of segment genotypes seems independent of the circulating variants, suggesting that genome segments persists independently and not in combination with other segments within the viral population. A factor that could account such outcome may be the frequent reassortment between PUUV variants, both closely- and distantly-related.

The most frequently occurring PUUV variants were always composed of copious genotypes. Transient variants seem to result from copious segment genotypes by accumulating nt substitutions, suggesting that viral genome segments are continuously drifting to provide the PUUV population with a diverse base from which to respond to new stressors. The three reassortant variants that were repeatedly detected throughout the study were composed of copious segment genotypes (Table 4), suggesting that they have a higher chance of co-infecting a host and/or have a pronounced ability to replace sporadic segment genotypes in a double infection scenario. Variants composed of sporadic segment genotypes are likely to be replaced when a co-infection occurred, thus only the dominant (i.e., copious) variants remain.

A substantial portion of co-circulating PUUV strains (19.1\%) possessed a reassortant genome. Altogether, 56 distinct reassortant variants were observed. The majority of reassortants (53 of 56) were transient, suggesting that reassortants did not outcompete parental variants. The analysis of a large number of PUUV genomes allowed for the detection of all six possible reassortant types (Table 6). This finding proved that all reassortant types are viable in natural conditions, agreeing with the in vitro reassortment of orthobunyaviruses [44]. Different PUUV reassortants were found with different frequencies: in the vast majority of reassortants $(95.6 \%)$, either $\mathrm{L}$ and $\mathrm{S}$ segments or $\mathrm{L}$ and $\mathrm{M}$ segments belonged to the same genogroup. Such a pattern of segments' combination suggests that reassortant types may differ in their replication efficacy. Unique reassortant variants were observed during every sampling event of the study (except 2006, when no PUUV was detected), and tended to be more prevalent in the autumn, even-tough the rates differences were not statistically significant. Seasonality of reassortment could be explained by seasonal variations in the age structure of the host population. During autumn, most bank voles are younger and recent infections

Table 6. PUUV Reassortants.

\begin{tabular}{llll}
\hline Combination of segments (S/M/L) & no. of genomes & Reassortant pattern & S-L/M \\
\hline ABA & 6 & & no. of genomes (\% of total number \\
of reassortants)
\end{tabular}

Pattern for combination of genome segment. S, M and L stand for Small, Medium and Large genome segments, respectively.

doi:10.1371/journal.pone.0064447.t006 
are more likely to occur during a narrow time-window. Hence, double infections in naive bank voles become more likely and the conditions more favorable for reassortment. Indeed, 11 of the 12 double infections were detected in the autumn samples, whether were shed as parental or reassortant strains remain unknown.

Apparently, only inter-species, inter-lineage or inter-genogroup PUUV reassortants could be clearly recognized. In nature, when genome segments are exchanged between closely related variants (i.e., between variant of the same genogroup), reassortants might be very difficult to detect. Such "imperceptible" reassortment could be a useful mechanism to maintain a steady state in the PUUV population. For example, it could counteract the effects of 'Muller's ratchet' [45-46]. Experiments with the segmented RNA $\Phi 6$ virus support the notion that reassortment can reduce an excessive mutational load in a population and hence helps to avoid the accumulation of deleterious effects [47-48].

To conclude, for the first time the microevolution of a hantavirus was studied throughout a population cycle of its host. Analyses of 356 PUUV genomes circulating in a bank vole

\section{References}

1. Plyusnin A, Beaty BJ, Elliott RM, Goldbach R, Kormelink R, et al. (2011) Bunyaviridae, pp. 731-734. In: Virus taxonomy: classification and nomenclature of viruses: Ninth Report of the International Committee on Taxonomy of Viruses. King AMQ Adams MJ, Carstens EB, Lefkowitz EJ (ed). San Diego: Elsevier Academic Press.

2. Plyusnin A, Vapalahti O, Lehväslaiho H, Apekina N, Mikhailova T, et al. (1995) Genetic variation of wild Puumala viruses within the serotype, local rodent populations and individual animal. Virus Res 38: 25-41.Plyusnin A (2002) Genetics of hantaviruses: implications to taxonomy. Arch Virol 147: 665-682.

3. Brummer-Korvenkontio M, Vaheri A, Hovi T, von Bonsdorff C-H, Vuorimies J, et al. (1980) Nephropathia epidemica: detection of antigen in bank vole and serological diagnosis of human infection. J Infect Dis 141: 131-134.

4. Vapalahti O, Mustonen J, Lundkvist A., Henttonen H, Plyusnin A, et al. (2003) Hantavirus infections in Europe. Lancet Infect Dis 3: 653-661.

5. The IUCN Red List of Threatened Species (2012). Available: http://www. iucnredlist.org/details/4973/0. Accessed 2013 April 21.

6. Brummer-Korvenkontio M, Henttonen H, Vaheri A (1982) Hemorrhagic fever with renal syndrome in Finland: ecology and virology of nephropathia epidemica. Scand J Infect Dis Suppl 36: 131-134.

7. Kallio ER, Begon M, Henttonen H, Koskela E, Mappes T, et al. (2009) Cyclic hantavirus epidemics in humans predicted by rodent host dynamics. Epidemics 1: 101-107.

8. Tersago K, Verhagen R, Vapalahti O, Heyman P, Ducoffre G, et al. (2011) Hantavirus outbreak in Western Europe: reservoir host infection dynamics related to human disease patterns. Epidemiol Infect 139(3): 381-390.

9. Bernshtein AD, Apekina NS, Mikhailova TV, Myasnikov YuA, Khlyap LA, et al. (1999) Dynamics of Puumala hantavirus infection in naturally infected bank voles (Clethrionomys glareolus). Arch Virol 144: 2415-2428.

10. Meyer BJ, Schmaljohn CS (2000) Persistent hantavirus infections: Characteristics and mechanisms. Trends Microbiol 8: 61-67.

11. Hardestam J, Karlsson M, Falk KI, Olsson G, Klingstrom J, et al. (2008) Puumala hantavirus excretion kinetics in bank voles (Myodes glareolus). Emerg Infect Dis 14: 1209-1215.

12. Lee HW, French GR, Lee PW, Baek LJ, Tsuchiya K, et al. (1981a) Observations on natural and laboratory infection of rodents with the etiologic agent of Korean hemorrhagic fever. Am J Trop Med Hyg 30: 477-482.

13. Lee HW, Lee PW, Baek LJ, Song CK, Seong IW (1981b) Intraspecific transmission of Hantaan virus, etiologic agent of Korean hemorrhagic fever, in the rodent Apodemus agrarius. Am J Trop Med Hyg 30: 1106-1112.

14. Gavrilovskaya IN, Apekina NS, Bernshtein AD, Demia VT, Okulova NM, et al. (1990) Pathogenesis of hemorrhagic fever with renal syndrome virus infection and mode of horizontal transmission of hantavirus in bank voles. Arch Virol Suppl 1: 57-62.

15. Sauvage F, Langlais M, Yoccoz NG, Pontier D (2003) Modelling hantavirus in fluctuating populations of bank voles: the role of indirect transmission on virus persistence. J Anim Ecol 72: 1-13.

16. Kallio ER, Klingström J, Gustafsson E, Manni T, Vaheri A, et al. (2006a) Prolonged survival of Puumala hantavirus outside the host: evidence for indirect transmission via the environment. J Gen Virol 87: 2127-2134.

17. Kallio ER, Poikonen A, Vaheri A, Vapalahti O, Henttonen H, et al. (2006b) Maternal antibodies postpone hantavirus infection and enhance individual breeding success. Proceedings of Royal Society B273: 2771-2776.

18. Kallio ER, Begon M, Henttonen H, Koskela E, Mappes T, et al. (2010) Hantavirus infections in fluctuating host populations: the role of maternal antibodies. Proc Roy Soc Biol Sci 277: 3783-3791. population over a five-year period allowed to study the mechanisms of viral genetic diversification and follow the fate of variants. The few PUUV variants that survived over several seasons did not show any sign of a founder effect. Collectively, the observations supported a quasi-neutral mode of PUUV microevolution with a steady generation of transient variants, including reassortants, and preservation of a few preferred genetic variants over several seasons/years.

\section{Acknowledgments}

We are grateful to Jukka Niemimaa and Liina Voutilainen for their precious help in the field. The Konnevesi Research Station provided excellent facilities for the field work.

\section{Author Contributions}

Conceived and designed the experiments: MR. Performed the experiments: MR A. Plyusnina. Analyzed the data: MR. Contributed reagents/ materials/analysis tools: HH A. Plyusnin. Wrote the paper: MR.

19. Razzauti M, Plyusnina A, Henttonen H, Plyusnin A (2008) Accumulation of point mutations and reassortment of genomic RNA segments are involved in the microevolution of Puumala hantavirus in a bank vole (Myodes glareolus) population. J Gen Virol 89: 1649-1660.

20. Razzauti M, Plysunina A, Sironen T, Henttonen H, Plyusnin A (2009) Analysis of Puumala hantavirus in a bank vole population in northern Finland: evidence for co-circulation of two genetic lineages and frequent reassortment between wild-type strains. J Gen Virol 90: 1923-1931.

21. Henderson WW, Monroe MC, St. Jeor SC, Thayer WP, Rowe JE, et al. (1995) Naturally occurring Sin Nombre virus genetic reassortants. Virology 214: 602610 .

22. Rodriguez LL, Owens JH, Peters CJ, Nichol ST (1998) Genetic reassortment among viruses causing hantavirus pulmonary syndrome. Virology 242: 99-106.

23. Sibold C, Meisel H, Kruger DH, Labuda M, Lysy J, et al. (1999) Recombination in Tula hantavirus evolution: Analysis of genetic lineages from Slovakia. J Virol 73: 8741-8749.

24. Sironen T, Vaheri A, Plyusnin A (2001) Molecular evolution of Puumala hantavirus. J Virol 73: 11803-11810.

25. Chare ER, Gould EA, Holmes EC (2003) Phylogenetic analysis reveals a low rate of homologous recombination in negative-sense RNA viruses. J Gen Virol 84: 2691-2730.

26. Gojobori T, Moriyama EN, Kimura M (1990) Molecular clock of viral evolution, and the neutral theory. Proc Natl Acad Sci USA 87: 10015-10018.

27. Lundkvist Å, Cheng Y, Brus Sjolander K, Niklasson B, Vaheri A, et al. (1997) Cell culture adaptation of Puumala hantavirus changes the infectivity for its natural reservoir, Clethrionomys glareolus, and leads to accumulation of mutants with altered genomic RNA S segment. J Virol 71: 9515-9523.

28. Razzauti-Sanfeliu M (2012) Microevolution of Puumala hantavirus in its host, the bank vole (Myodes glareolus). Available: https://helda.helsinki.fi/handle/ 10138/29616. Accessed 2013 April 21.

29. Hall TA (1999) BioEdit: a user-friendly biological sequence alignment editor and analysis program for Windows 95/98/NT. Nucl Acids Symp Ser 41: 95-98.

30. Librado P, Rozas J (2009) DnaSP v5: A software for comprehensive analysis of DNA polymorphism data. Bioinformatics 25: 1451-1452

31. Felsenstein J (1993) PHYLIP [Phylogeny Inference Package], 3.66 version. Distributed by the author. Department of Genetics, University of Washington, Seattle.

32. Bandelt H-J, Forster P, Röhl A (1999) Median-joining networks for inferring intraspecific phylogenies. Mol Biol Evol 16: 37-48.

33. Martin D, Rybicki E (1999) RDP: detection of recombination amongst aligned sequences. Bioinformatics 16(6): 562-563.

34. Lole KS, Bollinger RC, Paranjape RS, Gadkari D, Kulkarni SS, et al. (1999) Full-length human immunodeficiency virus type 1 genomes from subtype Cinfected seroconverters in India, with evidence of intersubtype recombination. J Virol 73(1): 152-60.

35. Provine WB (2004) Ernst Mayr: Genetics and speciation. Genetics 167(3): 10416.

36. Escutenaire S, Chalon P, Verhagen R, Heyman P, Thomas I, et al. (2000) Spatial and temporal dynamics of Puumala hantavirus infection in red bank vole (Clethrionomys glareolus) populations in Belgium. Virus Res 67(1): 91-107.

37. Olsson GE, White N, Ahlm C, Elgh F, Verlemyr A-C, et al. (2002) Demographic factors associated with hantavirus infection in bank voles (Clethrionomys glareolus). Emerg Infect Dis 8(9): 924-929.

38. Plyusnina A, Plyusnin A (2005) Recombinant Tula hantavirus shows reduced fitness but is able to survive in the presence of a parental virus: analysis of consecutive passages in a cell culture. Virology 2: 12. 
39. Jääskeläinen KM, Plyusnina A, Lundkvist Å, Vaheri A, Plyusnin A (2008) Tula hantavirus isolate with the full-length ORF for nonstructural protein NSs survives in interferon-competent cells for more consequent passages than the isolate having truncated NSs ORF. Virol J 5: 3.

40. Ojosnegros S, Beerenwinkel N, Antal T, Nowak MA, Escarmís C, et al. (2010) Competition-colonization dynamics in an RNA virus. Proc Natl Acad Sci USA 107(5): 2108-12.

41. Plyusnina A, Aberle SW, Aberle JH, Plyusnin A (2006) Genetic analysis of Puumala hantavirus strains from Austria. Scand 38(6-7): 512-9.Posada D (2008) jModelTest: Phylogenetic Model Averaging. Mol Biol Evol 25: 1253-1256.

42. Razzauti M, Plyusnina A, Niemimaa J, Henttonen H, Plyusnin A (2012) Cocirculation of two Puumala hantavirus lineages in Latvia: A Russian lineage described previously and a novel Latvian lineage. J Med Virol 84(2): 314-318.
43. Plyusnina A, Razzauti M, Sironen T, Niemimaa J, Vapalahti O, et al. (2012) Analysis of complete Puumala virus genome, Finland. Em Infect Dis 18 (12): 2070-2072.

44. Pringle CR, Lees JF, Clark W, Elliott RM (1984) Genome subunit reassortment among Bunyaviruses analysed by dot hybridization using molecular cloned complementary DNA probes. Virology 135(1): 244-56.

45. Muller HJ (1932) Some genetic aspects of sex. Am Nat 66: 118-138.

46. Muller HJ (1964) The relation of recombination to mutational advance. Mut Res 1: 2-9.

47. Chao L, Tran TR, Matthews C (1992) Muller's ratchet and the advantage of sex in the RNA virus $\Phi 6$. Evolution 46: 289-299.

48. Chao L, Tran TT, Tran TT (1997) The advantage of sex in the RNA virus $\Phi 6$. Genetics 147: 953-959. 